\title{
Negros pingos nos "is": djeli na África ocidental; griô como transcriação; e oralidade como um possível pilar da cena negra
} Black dotted “i's": djeli in West Africa; griot as
transcreation; and orality as a possible column of black
scene
Toni Edson Costa Santos ${ }^{1}$ 


\section{Resumo}

O presente artigo discute a valoração dada a palavras como negro, griô, que foram usadas num sentido negativo e hoje podem possuir outra leitura. Essas terminologias passaram? por uma ressignificação em que agentes negros tem pleiteado outro valor, positivo. $O$ texto apresenta o contador de histórias, genealogista, entre outras funções, presente na África Ocidental, chamado de djeli. O texto expõe que para ser djeli é preciso nascer djeli. Sua transcriação para o termo griô pode ser positiva, entendida a transculturação que ocorre. $\mathrm{O}$ texto aproxima Teatro e Contação de Histórias, e indica como a oralidade africana pode conduzir a cena negra. .

Palavras-chave: Teatro Negro; djeli; griô; oralidade.

\section{Abstract}

This article discusses the value attribute to words like black or griot, which were used in a negative sense and today may have another reading. These terminologies underwent a redefinition through which black agents have claimed another now positive value. The paper presents the storyteller, as genealogist, among other functions, present in West Africa, that is called djeli. The text exposes that to be djeli one must be born djeli. Its transcreation as griot may be positive, if the transculturation that takes place is understood. The text approaches theatre and storytelling, and points out how the African orality may inspire black artists within the performing arts.

Keywords: Black Theatre; djeli; griô; orality. 
Um assaltante invade a sua casa com armas possantes, mata familiares seus, estupra, transmite doença, rouba seus pertences, faz você trabalhar para ele obedecer suas ordens, esse assaltante pode, se ele for fisicamente diferente de você, atribuir essas diferenças a superioridade em relação a você, acreditar nisso e fazer até você crer nos argumentos dele, e ele pode também escrever livros e mais livros, produzir filmes e mais filmes, e ensinar para gerações e gerações, através de vários meios, que você é inferior e ele é superior a você por conta das diferenças fenotípicas (Cuti, 2010, p. 43).

\section{A palavra "negro"}

Esse artigo se propõe a analisar truques "retóricos" que circunscrevem a performance negra e em alguns momentos geram conflitos teóricos. A proposta é elucidar questões, propor reflexão sobre o peso de algumas palavras que retiradas de seu contexto podem causar dúvidas. A primeira dessas palavras inicia e termina o título, a terminologia, negra, negro. O escritor Luiz Cuti problematiza essa questão no seu texto, "Quem tem medo da palavra negro?", onde está contida a epígrafe acima. O autor coloca que "a humanidade nasceu na África". Dessa forma somos todos afrodescendentes. Mas o que o Movimento Negro tenta é exatamente ressignificar a terminologia "negro", antes proferida pejorativamente. Cuti nos fala sobre a escolha e a dinâmica das palavras:

As palavras trazem conteúdo, têm suas histórias no idioma, seus significados e suas morfologias não são para sempre. É por isso que elas são escolhidas ou rejeitadas. [...] Tendo a palavra em foco servido para ofender, no momento em que o ofendido assume-se dizendo "eu sou negro", o que ocorre é que ele dá a ela outro significado, ele positiva o que era negativo (Cuti, 2010, p 46).

O que Cuti e o Movimento Negro na diáspora propõem é uma mudança de paradigma. Não existe um país africano chamado "Negrolândia", mas esse adjetivo proferido atualmente é um grito de resistência. Cuti diz ainda que "afro-brasileiro, portanto, são todos os brasileiros [...] do ponto de vista científico e não social" e o prefixo "afro" não representa a pessoa humana da mesma forma que a palavra "negro":

Esta diz de pronto sobre o fenótipo: pele escura, cabelo crespo, nariz largo e lábios carnudos. Variações nesses itens são infinitas. "Afro" não necessariamente incorpora tal fenótipo, sobre o qual incide a insânia branca do racismo. Branca porque é dos brancos. Um "afro" pode ser branco. Há milhões deles. No "afro", o fenótipo negro se dilui (Cuti, 2010, p. 43).

O discurso de Cuti é radical (possui raízes profundas) e necessário. O professor e diretor cubano Julio Moracen Narranjo, coloca num patamar semelhante as palavras "negro" e "afrodescendente", mas nos instiga, como Cuti, a refletir sobre a necessidade de repensar o uso da palavra "negro". Júlio Moracen afirma que "somente os afrodescendentes podem se chamar de negros"

Seus ancestrais eram simplesmente africanos, sendo que ainda hoje falam de si mesmos como Dogon, Zulu, Massai, Ibo, etc. [...] 
Se é negro, afrodescendente, é porque essa identidade foi herdada da escravidão: todo africano na América tem sido considerado nada mais que um negro. Assim foi visto e categorizado pelo colonizador e esta categorização agora deve ser assumida como reivindicação orgulhosa de identidade consciente como cultura de resistência. [...] Sou negro! (Narranjo, 2011,7 p.5).

A atriz e pesquisadora Priscila Preta, investiga o que pode ser considerado um marco na utilização do termo "negritude" para se referir à elementos provenientes da cultura africana. Ela atribui a definição ao pan-africanista Leopold Sédar Senghor. Segundo Priscila:

Senghor foi poeta, ativista africano, político, e posteriormente, o primeiro presidente pós-independência do Senegal. Não foi ele o primeiro poeta a apresentar a palavra negritude em sua produção, pois o martinicano Aimé Césaire, em 1938, a revelou no seu livro de poemas. Mas foi Senghor quem a definiu como o "conjunto de valores culturais e espirituais africanos", esses valores, independentemente de nacionalidade ou território, estão presentes tanto no interior da própria África quanto nas diásporas africanas. (Preta, 2011, p. 88).

\section{Transculturação e transcriação}

O professor Julio Moracen avança na discussão relacionando inclusive a terminologia "negra" ao Teatro, como já havia feito Leroi Jones (Amiri Baraka): "Na década de 60, o poeta e dramaturgo negro Leroi Jones falava em fazer um teatro negro militante para que a população negra entendesse seu próprio mundo." O que une o discurso desses autores é a necessidade de ressignificar a palavra "negro" e assumir que a arte que fazemos é negra. Dessa maneira, a palavra "negra" e o termo "negro" têm passado por um processo de transculturação/transcriação, onde o que outrora era negativo está sendo positivado. Julio Moracen, em oposição ao conceito de aculturação fala do termo "transculturação", trazido por Fernando Ortiz para descrever manifestações negro-cubanas. Segundo Moracen, esse termo só era utilizado por Fernando Ortiz na década de 40 e na década de 70 retorna nos estudos de psiquiatria transcultural (Narranjo, 2011, p. 69). Através da transculturação, no embate entre as culturas, "permitia entender como as culturas se encontravam, nascendo daí uma nova cultura, a partir do que cada uma podia oferecer de melhor" (Narranjo, 2011, p. 69). O pesquisador diz que:

Para Fernando Ortiz, a transculturação supunha a existência de três momentos indissolúveis: aculturação - o contato com novos segmentos culturais; desculturação - o processo de aculturação em sua segunda fase, o abandono que cada cultura faz de alguns de seus elementos; e transculturação - um processo de transformação que dava lugar a uma ressignificação de novas realidades culturais (Narranjo, 2011, p. 69).

Moracen também cita a terminologia transcriação, assumida pelo poeta brasileiro Haroldo de Campos inspirado nos estudos de Fernando Ortiz, em que para cada nova tradução, ele se considerava transcriador, por estar trazendo um produto novo, uma nova obra (Narranjo, 2011, p. 69). Segundo Júlio Moracen, Fernando Ortiz amplia essa discussão transcultural utilizando o termo "contraponteio", que viria da 
música e das ciências sociais para reafirmar a ressignificação das palavras de culturas diferentes. Mas prefiro aqui utilizar o termo transcriação para designar o processo pelo qual tem se transformado a palavra "negro" e como pode ser encarada na diáspora o termo "griô". Essa palavra é uma tradução ocidental para contadores de histórias africanos, que se chamam, entre si, de djeli.

\section{Teatro e contação de histórias}

Mas antes de tecer comentários sobre o termo djeli, vou argumentar quanto à aproximação/complementaridade entre o Teatro e a Contação de Histórias. A arte milenar de contar histórias vem sendo pesquisada por atores e diretores na e são muitas as indicações de como contar histórias. Grande parte desses "manuais" está calcado numa cultura eurocêntrica que estabelece princípios teatrais do ocidente para estimular o ato performático de contar histórias. O contador de histórias contemporâneo cruza conceitos dramáticos e épicos ao passar por muitas personagens mantendo uma relação direta com o público. Conceitos como presença e verdade cênica (Stanisláviski), e estranhamento (Brecht) são recorrentes em discussões desse ramo espetacular. Sobre os limites da contação de histórias e do teatro, acredito que as duas artes sejam complementares, senão muito parecidas. Elvia Perez(2012), num artigo do livro $A$ arte de encantar: o contador de histórias contemporâneo e seus olhares, organizado por Fabiano Moraes e Lenice Gomes, intitulado "Narração oral ou Teatro?", busca estabelecer alguns dos limites possíveis dos dois campos. A autora afirma que:

As diferenças eram evidentes; o narrador, diferentemente do ator, não incorpora um personagem, mas o 'vive brevemente' em sua narrativa. Da mesma forma, a narrativa não utiliza a quarta parede do teatro, mas sim a comunicação direta com o público. O relato não usa elementos, nem cenário, porque ocorre em qualquer lugar público, já que é finalmente oralidade (Gomes \& Moraes, 2012, p. 153).

Essa citação diz respeito à contraposição de um tipo de teatro ao ato de contar histórias, mas, da mesma maneira que há muitas formas de narrar, há muitas formas de fazer teatro. Elvia Perez lembra que a essência da narrativa oral é o discurso, mesmo que haja diálogo em alguns contos. Mas a figura do narrador não pode desaparecer. Normalmente, o relato do conto é algo que já aconteceu e "embora seja pessoal e contado em primeira pessoa, [...] mesmo que tenha sido em um passado recente, é passado, por isso eu pude contá-lo".

A história possui ações verbais que não correspondem às ações físicas ao contá -la, pois ocorrem na imaginação daquele que conta e daquele que a ouve. O que faz o narrador, se necessário, são os deslocamentos pela cena, não ações físicas. [...] Há muitas maneiras de se contar um conto, tantas quantas forem os contadores de histórias; continua sendo narração oral se sua essência é mantida, embora varie a forma de apresentá-la (Gomes \& Moraes, 2012, p. 156).

Uma forma de teatro que pode se utilizar de muitos princípios e atributos do 
ato de contar histórias é o teatro popular feito em espaços abertos, porque parte da premissa de que não há quarta parede, e as relações entre ator e plateia são muito próximas. Elvia Perez apresenta também essa aproximação quando afirma que o "narrador oral conta com a história usando a gestualidade, o tom de voz, o olhar ou o movimento" e as formas de "adaptabilidade e versatilidade da narração de contos, estas já estavam presentes no teatro popular". A autora cita Petr Bogatiev em seu artigo "Semiótica do Teatro Popular", o autor:

comenta que, diferentemente do teatro culto, o teatro popular define o espaço cênico pela presença do ator sem necessidade de outro tipo de elemento, nem pano de fundo, e tem uma ligação mais estreita entre o ator e o público, o que requer que o autor se dirija diretamente para o público (Gomes \& Moraes, 2012, p. 164-165).

E é exatamente dessa maneira que o djeli, contador de histórias encontrado na África Ocidental, se relaciona com seu público, diretamente e contando com sua expressão e por vezes com instrumentos musicais. Apesar das aproximações sobre os limites do ofício teatral e da contação de histórias, muitos contadores de histórias preferem não se assumirem atrizes e atores, devido às especificidades da forma de treinamento e uma visão de teatro que limita a percepção de quem não pratica essa arte. Nesse sentido, uma das diferenças entre a função de ator e a de contador de histórias se dá pela regulamentação da profissão. O teatro tem uma legitimidade profissional há muitos anos e somente há cerca de 30 ou 40 anos, há uma movimentação para considerar a contação de histórias como profissão.

\section{Oralidade, djeli e griot}

Mas esse retorno ao ato profissional de contar histórias ${ }^{2}$ no Brasil também tem assumido a grande presença da oralidade africana na estrutura de nossa nação e tem-se buscado aproximações entre as várias formas de contar histórias na África e o que temos feito aqui.

É preciso atentar que, ao se falar de contadores de histórias em África, falamos de culturas essencialmente orais, em que a oralidade não significa uma ausência de habilidade com a escrita, mas uma atitude diante da realidade.

Todo som que produzimos são abarcados no campo da oralidade. Para Elvia Perez, oralidade abrange "[...] desde o choro de um bebê com fome, até o monólogo psicanalítico e filosófico dos seres humanos" (Gomes \& Moraes, 2012, p.159). A grande maioria dos grupos étnicos africanos transmite seu aprendizado através da oralidade, há tradições orais em diversos segmentos dessas sociedades, embora extam, em alguns povos, castas em que as pessoas são formadas para contar histórias, e

\footnotetext{
2 Segundo Celso Sisto, tem ocorrido um movimento mundial da valorização e profissionalização do contador de histórias, que ele chama de "boom" dos contadores de histórias, desde a década de 70 (Sisto, 2005, p. 79-84). Felícia de Oliveira Fleck escreve uma dissertação sobre A profissionalização do contador de histórias contemporâneo, onde analisa o movimento de contação de Santa Catarina, entrevista contadores de histórias profissionais e inclusive alguns
}

com pesquisa em contos africanos (Fleck, 2009, p. 91). E Gislayne Matos situa na década de 1970 o que ela chama de "volta dos contadores de histórias" e cita grandes festivais e encontros que marcaram esse retorno da arte de contar histórias em meio urbano (Matos, 2005, p. XVII-XXI). 
resguardar a genealogia, como é o caso do djeli. Há tradições orais entre os ferreiros e tecelões da África Ocidental, mas sua função está voltada para a arte da forja ou do tecer. Para o djeli, sua função na sociedade é ser depositário da palavra, essa é a matéria prima de seu artesanato. No Brasil, eles são conhecidos como griots, apesar de, entre eles não se chamarem dessa maneira. Eles resguardam a memória de muitas gerações, a tradição oral é a razão de existir dessa casta. Djibril Tamsir Niane, em sua versão da história de Sundjata, um grande épico da cultura mandinga, ouvida de Mamadou Kouyaté afirma que:

Durante longos anos ele aprendeu a arte oratória na História; além disso, é juramentado e somente ensina o que ordena a sua "corporação", já que - como dizem os griots - "Toda ciência verdadeira deve ser um segredo". [...] é mestre na arte das perífrases, fala empregando fórmulas arcaizantes ou transpõe os fatos em lendas que divertem o público, mas de cujo sentido secreto o vulgo jamais se apercebe (Niane, 1982, p. 5).

Em sua narrativa escrita, o autor assume a voz daquele que o contou a história e ainda explica mais sobre esse uso da palavra:

A arte da palavra não apresenta qualquer segredo para nós; sem nós, os nomes dos reis cairiam no esquecimento; nós somos a memória dos homens; através da palavra, damos vida aos fatos e façanhas dos reis perante as novas gerações (Niane, 1982, p. 11).

Portanto, embora o termo oralidade seja abrangente e compreenda toda e qualquer articulação de sons, o que interessa nesse artigo é a oralidade transformada em palavra pelo corpo.

Esse entendimento de oralidade já é praticado há séculos na cultura mandinga (África Ocidental) e com o movimento recente de profissionalização do contador de histórias no ocidente, essas leituras vêm sendo teorizadas. Muitas dessas teorias, acabam citando o termo griot. Esta palavra parece ter diversas origens, alguns dizem que vem do termo "guirilô", do francês, outros dizem que vem do termo "criado", do português ${ }^{3}$. Thomas Hale (Hale, 2007, p. 357-366) compreende e destaca essas possíveis origens e ainda possui uma teoria que relaciona a origem do termo griot com o Império de Gana, no século XI, em função de escravos de Gana levados para o Marrocos, sendo que alguns se destacavam, pelas suas qualidades verbais e musicais, que teriam sido chamados de "group of guineos" na Espanha, que teria derivado para "guiriots" e depois "griots"4. 
Acredito que essa teoria se espalha na Europa e inclusive chega ao Brasil com muita força, através da Ação Griô Nacional ${ }^{5}$ surgida em 2006 no interior da Bahia, até a luta pela implementação da Lei Griô Nacional ${ }^{6}$, de valorização dos mestres da cultura popular no Brasil. Acho importante destacar que entendo todo o movimento brasileiro em torno dessa terminologia, respeito, e concordo com sua utilização, desde que seja encarada com uma forma de transcriação. A palavra "griô" não existe em nenhuma língua africana, e foi uma terminologia imposta pelos colonizadores.

O djeli traz posturas éticas e ensinamentos presentes em alguns povos africanos. A terminologia vem da cultura mandê, mandingue (francês) ou cultura mandinga, em português. Thomas A. Hale (2007), fala que o Império Mande tinha uma extensão de cerca de 1500 quilômetros de leste a oeste e cerca de 1000 quilômetros de norte a sul, e que apesar de nem todos os povos serem mandinga, sua influência cultural é a mais importante7 (Hale, 2007, p. 15). Segundo Amadou Hampatê Bâ e Juliana Jardim, o termo "diele" é proveniente da língua bambara (Barboza, 2008, p. 138). Já "djeli" vem da língua maninka, segundo Isaac Bernat (Bernat, 2008, p. 67). Os djeliw (plural de djeli) têm amplos poderes no que concerne ao uso da palavra e são profissionais contadores de histórias, havendo os djeliw músicos (compositores que cantam suas histórias acompanhados de instrumentos diversos); djeliw embaixadores (que intercedem em nobres famílias, sendo bastante gratificados por resolver ou evitar desavenças); e há os djeliw genealogistas, (poetas e historiadores que mapeiam com suas histórias a árvore genealógica de famílias importantes). Os três tipos têm bastante liberdade com a palavra e são dotados de prodigiosa memória. Segundo Isaac Bernat: "O griot nasce griot e seu legado passa de pai para filho, um imenso rio de histórias, ditados e metáforas onde pode pescar aquilo que alimentará a consciência e o espírito de quem o procura" (Bernat, 2008, p. 33).

Já Ricardo Ribeiro, citando Carlos Vaz, afirma que:

O griot africano é homem de muitas facetas, é músico, cantador de histórias, menestrel e genealogista; depositário das tradições africanas. [...] Ele é o tocador do "pluriarco", um dos mais antigos instrumentos africanos. "O narrador-ator ou o griot faz muitas vezes o papel do ator total, que recria o drama, ao mesmo tempo que interpreta sozinho todos os papéis (deuses, homens, animais) (Vaz, 1978, p. 17-18 e Rodrigues, 2011, 19).

\footnotetext{
5 "AAção Griô Nacional nasceu em 2006 como projeto criado e proposto pelo Ponto de Cultura Grãos de Luz e Griô, da Bahia, ao programa Cultura Viva da Secretaria de Cidadania Cultural do Ministério da Cultura. A Ação Griô é uma rede que envolveu 130 projetos pedagógicos de diálogo entre a tradição oral e a educação formal, mais de 750 griôs e mestres bolsistas de tradição oral do Brasil, 600 escolas, universidades e outras entidades de educação e cultura e 100 mil estudantes de escolas públicas. [...] 0 abrasileiramento da palavra Griô trata-se de uma reinvenção simbólica que unifica os termos que referenciam os representantes das tradições em diversos países, grupos étnicos e regiões. Depois de abrasileirado em 1998, o termo ganhou no Brasil mais de 588.000 citações e páginas na internet em nível nacional e internacional, relacionadas com as tradições orais." Estas informações podem ser encontradas em: http://www.acaogrio.org.br/acao-grio-nacional/historico-acao-grionacional/\#saiba-mais

6 "Um dos maiores resultados qualitativos conquistados pela Rede Ação Griô foi a mobilização nacional em busca de 1 milhão de assinaturas para apresentar ao Poder Legislativo Federal o projeto de iniciativa popular: a Lei Griô
}

Nacional, já em tramitação no Congresso através do PL 1.786/2011. O resultado da mobilização gerou a minuta da Lei Griô Nacional que foi eleita na íntegra como uma das 32 prioridades da política do Ministério da Cultura do Brasil na Conferência Nacional de Cultura (março de 2010) entre mais de 600 propostas, envolvendo mais de 200 mil dirigentes culturais, representantes de conselhos de cultura e comunidades de base em todo o país." Estas informações podem ser encontradas em: http://www.acaogrio.org.br/acao-grio-nacional/historico-acao-grio-nacional/\#saiba-mais

7 "Another reason for the negative meaning attached to griot is the dominance of the Mande cultures in West Africa. They cover an area of nearly 1,500 kilometers from west to east and almost 1,000 kilometres from north to south. Not all people in this area are Mande, but the Mande influence is the most prevalent. For this reason there is a tendency on the part of the comparatively large number of scholars interested in these interrelated peoples to take a Mandecentric view of the profession and call for the exclusive use of the Mande terms, jeli or jali" (Hale, 2007, p. 15). 
Apesar de haver bibliografia escassa, em português, sobre as figuras de contadores de histórias em África, no tocante à figura do djeli há acesso à bibliografia traduzida de boa qualidade, como comprovam os estudos de Amadou Hampaté Bâ. Segundo Bâ, o griot é uma "corporação profissional compreendendo músicos, cantores e sábios genealogistas itinerantes ligados às famílias cuja história cantam e celebram. Podem também ser simples cortesãos" (Bâ, 2003, p. 13). Thomas Hale realiza entrevistas com mais de 100 djeliw desde 1964 (Hale, 2007, p. 7) traz em seu livro Griots e Griottes uma lista com mais de 10 funções para o djeli, e entre elas estão as de genealogista, historiador, contador de histórias; conselheiro, orador, diplomata, mediador de conflitos, intérprete de várias línguas, músico, compositor, professor, repórter, supervisor, testemunha em muitas cerimônias, e cantor de louvores (Hale, 2007, p. 19). Algumas dessas profissões no Ocidente estão muito próximas, mas Hale faz uma diferenciação de cada uma delas sob o ponto de vista da cultura mandinga (Hale, 2007, p. 18-58).

Segundo Amadou Hampatê Bâ:

O nome dieli em bambara significa sangue. De fato, tal como o sangue, eles circulam pelo corpo da sociedade, que podem curar ou deixar doente, conforme atenuem ou avivem os conflitos através das palavras e das canções (Bâ, 1980, p. 204).

Através dos discursos proferidos por Amadou Hampaté Bâ podemos perceber algumas nuances da figura do djeli. Num minicurso com o professor da UFBA Mahomed Bamba(2011), ele falou sobre a teoria La griotique, de Niango Porquet (1974), da Costa do Marfim, onde ele foca a figura do "griot" da África Ocidental subsaariana e busca correspondentes em outras culturas africanas. Segundo ele, "la griotique" surge do teatro e da antropologia e seria a "expressão dramática na qual se integram de forma metódica e harmoniosa, a palavra, o canto, a mímica, a linguagem corporal, o movimento, a literatura e a história"8. Dessa forma, toda cultura, africana ou não, pode ter representantes dessa vertente desde que trabalhe com a oralidade, seja artista polivalente reconhecido em sua comunidade e atue como uma espécie de preceptor/educador.

Sob esse ponto de vista, concordo com a leitura feita no Brasil do termo "griot" e o aportuguesamento "griô". Mas para falar do contador tradicional que vem de uma casta, o termo djeli me parece o mais apropriado.

\section{Os djeliw Kouyaté e a crítica ao termo griot}

Na formação do Império do Mali, de onde surge o épico de Sundjata, toda família, principalmente os nobres, possuíam um djeli que guardava a memória da comunidade, mas atualmente esse tipo social tem ocupado outras funções. $\mathrm{O}$ ator e

${ }^{8}$ Anotações minhas do curso de Mahomed Bamba, (2011) 
djeli Sotigui Kouyaté chega a falar de cerca de 40 tipos de djeli diferentes (Kouyaté, 2006). Na entrevista ao Festival de Palhaços "Anjos do Picadeiro 5", o ator afirma que cada família tem o seu djeli. "Cada família tem o seu griot. Cada cidade tem o seu griot" (Kouyaté, 2006). Apesar da afirmação de Sotigui Kouyaté, temos mais notícias de djeliw de famílias reais, como afirma Camara Laye:

[...] as ordens do rei, as proclamações eram transmitidas por vozes humanas, segundo um costume multisecular. Os anunciadores públicos, isto é, os griôs constituíam naquela época, uma verdadeira classe. Eram eles que, pelo único trabalho da memória, detinham os costumes, as tradições e os princípios de governos dos reis. E cada família real tinha um griô a quem cabia a conservação da tradição (Laye, 1978, p. 12). ${ }^{9}$

Cada cidade tem um, há agremiações de djeliw e por vezes há batalhas entre os chefes da corporação, mas: "o Kouyaté nunca é chefe, porque começou com a gente. Nós somos os árbitros"(Kouyaté, 2006). Na entrevista, Sotigui Kouyaté fala da figura do djeli, comparada ao nosso palhaço ou bufão, pois apesar de tratar de temas sérios, é preciso haver o alívio cômico:

O palhaço está em todos os lugares, só muda o nome. Ele é indispensável. É uma mensagem muito importante para o público. Se você vê que o público não está gostando, bota um pouco de humor e sua mensagem vai passar mais fácil. Se faz na gravidade, todo mundo se fecha. As pessoas se fecham, levantam e vão embora ou então ficam distantes (Kouyaté, 2006).

E como afirma Mikhail Bakthin, o "riso acompanhava também as cerimônias e os ritos civis da vida cotidiana: assim, os bufões e os 'bobos' assistiam sempre às funções do cerimonial sério, parodiando seus atos" (Bakthin, 1987, p. 4).

O djeli tem essa dupla função de transmitir e divertir, e ainda em comparação ao bufão, ele continua ocupando suas funções em todas as circunstâncias da vida, "numa fronteira entre a vida e a arte" (Bakthin, 1987, p. 7). Sotigui afirma também que os "griots" têm muito poder "mas nunca contra os outros, contra eles mesmos". Há sempre conflitos entre eles, mas nunca entre eles e a sociedade. Para alguns africanos, esse termo "griot", é um insulto, segundo Thomas Halle(2007), que explica o grande alcance desse termo não pela teoria "griótica", mas através de um movimento iniciado nos EUA. "Alguns africanos do oeste percebem que a palavra pode insultar e dizem que não deveria ser utilizada porque não aparece em nenhuma língua africana. Mas para muitos afro-americanos, griots constituem a mais alta e inexorável ponte com suas tradições culturais (Hale, 2007, p. 8) ${ }^{10}$.

Eu sempre tive uma certa preocupação com a utilização do termo do colonizador. A contadora de histórias Keu Apoema fez um intercâmbio em Burkina Faso em 2011. Pedi para Keu que perguntasse o que os contadores achavam do termo griot e 
como eles costumavam se chamar. Hassane Kouyaté disse que preferia ser chamado de djeli, porque "griot" era o nome do colonizador. Francois Moise Bamba, da casta dos ferreiros, quando contou a história da origem do djeli, disse que preferia esse termo ao mais conhecido ${ }^{11}$. Quando pude entrevistar François Moise Bamba, em 2015, ele me deu a seguinte resposta em relação ao termo "griot":

Antes de tudo, acho que é uma desonestidade do branco, que não conhece a paternidade das coisas de África. Veja bem, não há um nome em diula para designar "computador", por isso nós vamos chamar de "computador-i", a "mesa" nós não temos um nome para chamar e chamamos "mesa-i" a "xícara", não temos como chamar e vamos chamar "xicara-ti". A gente faz a inclusão desse "i", "i", "ti" para que a criança saiba que essa palavra vem do francês, mas não faz parte de sua cultura. Mas o branco, ele vai forçosamente... ele chega e vê um instrumento que se chama Ngoni, ele vai dizer: "-Não, essa é a guitarra africana!". [...]É semelhante com a palavra griot para mim, ela é...ela não existe a não ser para o branco...eles se chamam de djeli, e por desconhecer o djeli eles em verdade tem necessidade de criar outra palavra para chamar o djeli, que não faz parte de sua cultura, que não é da sua cultura. Na verdade djeli quer dizer sangue, sangue como elo, sangue como vida, sangue como singularidade, e todo mundo tem o sangue...você vê? É forte!!! Mas griot é muito fraca para mim, não diz nada, [...] mas quando eu digo djeli, passo a pensar em minhas veias, me leva a falar e pensar em procriação, me faz pensar na vida e na morte, dentro da palavra djeli!! (Bamba, 2015). ${ }^{12}$

Toumani Kouyaté, em uma de suas oficinas em São Paulo em 2013 afirmava que existem os "griots", mas "os Kouyate são djeli, mestre de griots. Griot é um animador público, ele brinca com todo mundo, até o rei. O griot pode transformar a palavra do djeili. Um Kouyaté pode ser um griot, mas não tem direito a palavra sagrada" (Kouyaté, 2013). Hassane Kouyaté fala um pouco do que seu avô fez com seu pai. Havia um determinado momento em que os franceses já estavam entre os burkinabês, e que não se podia mais retirá-los de lá. O pai de Sotigui pediu para que seu filho fosse até eles, que conhecesse como eles pensavam, mas sem nunca perder suas raízes. Sotigui fez o mesmo com seu filho Hassane.

\section{Griô como transcriação e a oralidade na cena negra}

Thomas Hale inicia seu livro destacando as várias maneiras como o termo "griot" tem sido usado atualmente. Ele traz nomes de coreografias como "Griot New York"; referencias a músicos como jazzistas "griots"; nomes de organizações culturais que trabalham com a palavra como "Griot Organization", L'Association des Griot de la Martinique"; em revistas e jornais, "Les Griots", fundada em 1938 no Haiti e "The Literary Griot" especializada em literatura africana e afroamericana nos EUA, livros, livrarias e editoras e em muitos textos que falam de identidade cultural (Hale, 2007, p. 2-4). Thomas Hale afirma que o primeiro registro escrito de um djeli data de 28 de julho de 1352, feito por um viajante do Marrocos que chegou a capital do império do

\footnotetext{
11 Toda essa história de origem e a preferência ao termo djeli podem ser encontradas em http://apoema.art.br/?p=790

12 Entrevista realizada com o coordenador do Festival Yeleen, de Burkina
}

Faso, François Moise Bamba, em sua edição de 2014/2015. 
Mali, e esse relato sobre djeliw do século XIV "é especialmente importante hoje porque evidencia que a tradição oral mantida por esses bardos é de pelo menos 7 séculos atrás (Hale, 2007,p. 1) ${ }^{13}$. Hale descreve depois um outro viajante, o americano Alex Haley que encontrou um djeli em 17 de maio de 1967 na Gâmbia, onde era a fronteira ao oeste do Império do Mali. "Lá, ele encontrou um homem griot ou jali, que originalmente recontou o que Haley relata ser a narrativa sobre a origem das raízes de sua família na África" (Hale, 2007, p. 1). O autor completa dizendo que para os americanos, aquelas palavras proporcionaram um "elo entre seus ancestrais americanos e a herança africana recentemente apagada pela escravidão" (Hale, 2007, p. 1) ${ }^{14}$. Talvez seja até mais provável que a influência do termo "griot" no Brasil venha dos EUA do que da Europa, mas a questão é que durante muito tempo e até hoje, o termo é usado sem uma reflexão profunda ou pelo menos ouvindo o que essa casta de contadores tem a dizer. Hale também afirma que:

Afro-americanos têm adotado o termo griot como um sinal de respeito por aqueles que sabem sobre o passado, são artistas polivalentes ou são simplesmente pessoas notórias. Idosos no Harlen foram descritos como griots numa carta para o New York Times por um membro local da Assembléia do Estado de Nova York (Hale, 2007, p. 4). ${ }^{15}$

Esse é exatamente o movimento de revalorização dos mestres do saber que se executa no Brasil, numa leitura de que eles são um elo entre a tradição brasileira e as influências orais africanas, uma transcriação em torno da tradução da palavra. Acho legítimo, para o fortalecimento de nossa identidade que o termo aportuguesado "griô" seja difundido e defendido no Brasil. Thomas Hale aponta pelo menos dois motivos para continuar usando em seu livro a terminologia "griot". O primeiro é porque o termo se espalhou em muitos países da diáspora com conotação positiva. "Ele entrou no vocabulário do Afro-americano de tal forma que seria impossível tentar suprimi-lo.[...] o termo griot é agora reconhecido em todo o mundo." (Hale, 2007,p.15). A segunda razão é que:

a natureza regional do griot termo e sua versão feminina griotte, na África Ocidental, ressalta o fato de que a profissão exerce algumas das mais antigas e importantes atividades culturais unindo as mais diversas pessoas, incluindo aquelas que não estão relacionados com o Mande (Hale, 2007, p. 15). ${ }^{16}$

\footnotetext{
13 "[...] the picture of the fourteenth-century gritos is especially importante today because it provides eidence that the oral tradition maintained by these bards at least seven centuries old. (Tradução nossa).

14 "There he encoutered a man of griot, or jali, origin who recounted what Haley reported to be a narrative about Haley's roots in Africa. For the americans, the words of this man provide a link between his American ancestors and an African heritage nearly erased by the slave trade." (Tradução nossa).

15 "African American are adopting the term griot as a sign of respect for those who know about the past, are artists in various media, or are simply high achievers. Elders in Harlem were described as griots in a letter to the New York Times from a local member of the New York State Assembly." (Tradução nossa).

16 "For two reasons, it seems inevitable that griot will continue to serve as the
}

generic term for these wordsmiths. First, griot has spread into many parts of the African diaspora, in particular the Caribean and United States, taking on extremely positive connotations for those who see the profession as a link to their ancestors. It has entered the vocabulary of African Americano such an extent that it would be impossible to try to suppress it. And like griots themselves who travel so widely, the term griot is now reconized around the word. Second, the regional nature of the term griot and its female counterpart giotte in West Africa underscores the fact that the profession carries out some of the oldest and most important cultural activities linking many diverse people, including those that are not related to the Mande" (Tradução nossa). 
Quando se fala especificamente do grupo de contadores da África Ocidental, eu prefiro me referir como djeli. Mas a apropriação e processo transcultural do termo "griô" ocorrido na diáspora tem seu peso e sua carga de significados muito fortes. Assim como a releitura/ ressignificação da palavra negro há algumas décadas. $\mathrm{E}$ é importante entender que essa negritude, enquanto "conjunto de valores culturais e espirituais africanos" (Preta, 2011, p. 88) se manifesta no Teatro Negro que fazemos. Julio Moracen nos diz que:

Identificar o Teatro Negro anos atrás exigia sempre uma preocupação conceitual diante de pesquisadores ocidentais que consideravam radical ou extremista qualquer produção sustentada por um estética negra. Partindo do adjetivo unido ao substantivo teatro, era ainda mais escandaloso. [...] Teatro negro está relacionado à identidade cultural do homem negro, este pode ser compreendido a partir de uma visão cronológica, de análise e de performances, com um movimento constituído por representantes espetaculares, obras e encenações dramáticas negro-africanas - da origem e da diáspora (Narranjo, 2011, p. 65).

Os textos criados coletivamente no Bando de Teatro Olodum/ BA e na Cia dos Comuns/RJ, partem de referenciais orais de atrizes e atores. Outros espetáculos e grupos de Teatro Negro possuem fonte em mitos orais, provenientes de religiões de matriz africana, como é o caso do NATA / BA. Há ainda os grupos, como o Caixa Preta /RS que realizam a releitura de textos europeus com componentes negros. Cito apenas alguns dos grupos que estiveram presentes nas discussões realizadas pelo Fórum de Performance Negra, nos anos de 2005, 2006, 2009, em Salvador. Nos Fóruns eram discutidos temas em torno da performance negra, e apesar de não ter havido em nenhum dos 3 uma discussão mais profunda sobre a temática da oralidade, o terceiro Fórum foi encerrado com a apresentação do grupo de Congado mineiro que gerou o livro Afrografias da Memória, da professora Leda Maria Martins. A professora assim descreve seu livro:

E assim, escrevi esta narrativa. Queria eu desenhar uma melopéia que traduzisse na letra escrita (impossível desejo!) o fulgor da performance oral, os matizes de uma linguagem sinestésica que conjugasse as palavras, os gestos, a música e o encantamento imanentes na materialidade signíca e significante dos cantares e festejos dos Congados; uma dicção que não elidisse o sujeito e o objeto, o sopro e o estilete, o ritmo e a cor. Mas a escrita se recobre de outros matizes e modulações e, mesmo quando recobre a sinestésica performance da oralidade, desvela-nos outras diferentes possibilidades de fruição e magia (Martins, 1997, p. 20).

A professora ainda considera como um elemento crucial para o referencial cultural de matriz africana, a presença da oralidade, que ela chama de "oralitura", uma construção oral de sociedades africanas, algumas vezes ágrafas por opção. Ela vê na reconstituição da memória e nos processos de "oralitura", outras formas de transcriação:

Se a realidade às vezes se vela, por um processo numinoso de ocultação, é a força da palavra, como aletbéa e da axé, do logos, enfim. [...] Nos Congados, a palavra, como hálito, condensa o legado ancestral, seu poder inaugural, e o movimento prospectivo da transcriação, num percurso curvilíneo, presença crivada de ausência, memória resvalada no esquecimento, tranças aneladas na própria 
enunciação zdo narrado. Assim, na oralitura dos Reinados negros, a memória, insinuante, se envieza nas falas, se esvazia e se preenche de sentido, como um lugar numinoso, pletora de significantes, do qual também indagamos: "afinal, o que fica das pegadas no chão da memória? fica o que significa, pode-se pensar. Ou talvez o contrário: o que significa passa a ficar (Martins, 1997, p. 22).

Assim como há influências de várias etnias de África no Brasil, e considerando que muitas delas possuem em seu contexto uma forte ligação com a cultura oral, as manifestações espetaculares e o Teatro Negro feito aqui podem extrair muito das fontes orais de nossos mestres de tradição, como é o caso dos Congados. Esses mestres podem e devem ser chamados de griôs, num processo objetivo de transcriação. E mesmo quando se queira aprofundar na cultura Mandinga, território onde transitam e recontam os djeliw, o termo griô funciona enquanto referencial. Não é possível chamar de djeli alguém que não seja proveniente de uma família, uma dinastia, uma casta, como é o caso dos Kouyaté, mas é possível positivar o negativo, acreditar no poder de uma oralidade dinâmica e transcriar o termo europeu "griô" como mola mestre do Teatro Negro Brasileiro.

\section{Referências}

BÂ, Amadou Hampaté. Aspects de la Civilization Africaine. Trad. Daniela Moreau. Paris: Présence Africaine, 1972.

BÂ, Amadou Hampaté "A Tradição Viva". In: KI-ZERBO, Joseph. História Geral da África. V. 1. São Paulo: Ática/Unesco, 1980.

BAKTHIN, Mikhail. A Cultura Popular na Idade Média e no Renascimento: o contexto de Francois Rabelais. São Paulo: Hucitec, 1987.

BARBOZA, Juliana Jardim. Vestígios do dizer de uma escuta (repouso e deriva na palavra). Tese de doutorado apresentada ao Programa de Pós-graduação em Artes Cênicas da ECA/USP. São Paulo: 2009.

BERNAT, Isaac Garson. O olhar do griot sobre o ofício do ator: reflexões a partir dos encontros com Sotigui Kouyaté. Tese de doutorado apresentada ao Programa de Pósgraduação em Teatro do Centro de Letras e Artes da UNIRIO. Rio de Janeiro: 2008.

BIÃO, Armindo. Na encruzilhada do ator-narrador: entre o teatro e a teoria. In: Rebento: Revista de Artes do Espetáculo. São Paulo: Unesp, 2010.

FARIAS, Paulo F. de Morais. Griots, louvação oral e noção de pessoa no Sahel. São Paulo: Casa das Áfricas (PUC/USP), 2004. 
CUTI, Luiz Silva. Quem tem medo da palavra negro? In: Oliveira, Jessé (org.). MATRIZ: uma revista de Arte Negra (Grupo Caixa Preta). Porto Alegre: Grupo Caixa Preta, 2010.

FORD, Clyde W. O herói com rosto Africano: mitos da África. Trad. Carlos mendes Rosa. São Paulo: Summus, 1999.

GOMES, Lenice \& MORAES, Fabiano(org.). A arte de encantar: o contador de histórias contemporâneo e seus olhares. São Paulo: Cortez, 2012.

HALE, Thomas A. Griots and Griotes: Masters of words and music. Bloomington: Indiana University Press, 2007.

HALL, Stuart. Da diáspora: identidades e mediações culturais. Organizado por Liv Sovik. Belo Horizonte: UFMG; Brasília: Representação da UNESCO no Brasil, 2003.

KOUYATÉ, Sotigui. Entrevista concedida ao Encontro de Palhaços Anjos do Picadeiro 5. Rio de Janeiro: 2006.

MATOS, Gislayne Avelar. A palavra do contador de histórias: sua dimensão educativa na contemporaneidade. São Paulo: Martins Fontes, 2005.

MATOS, Gislayne Avelar SORSY, Inno. O ofício do contador de histórias: perguntas e respostas, exercícios práticos e um repertório para encantar. 2.ed. São Paulo: Martins Fontes, 2007.

MARTINS, Leda Maria. Afrografias da memória. São Paulo: Perspectiva. Belo Horizonte: Mazza Edições, 1997.

NARRANJO, Júlio Moracen. O segredo da sombra. In: Oliveira, Jessé (org.). MATRIZ: uma revista de Arte Negra (Grupo Caixa Preta). Porto Alegre: Grupo Caixa Preta, 2010.

NARRANJO, Julio Moracen. Capulanas em Contraponteio: onde começa ação na aurora dum destino. In: SILVA, Saloma Salomão Jovino da \& Capulanas (org.). \{EM\} GOMA: dos pés à cabeça, os quintais que sou. São Paulo: Capulanas, 2011.

ORTIZ, Renato. Cultura Brasileira e Identidade Nacional. São Paulo: Brasiliense, 2006.

ORTIZ, Renato. Românticos e folcloristas. São Paulo: Olho d'Água, 1979.

PRETA, Priscila. Arte Negra e Política. In: SILVA, Saloma Salomão Jovino da \& Capulanas (org.). \{EM\}GOMA: dos pés à cabeça, os quintais que sou. São Paulo: Capulanas, 2011.

RODRIGUES, Ricardo Alexandre Ribeiro. Busca de princípios para uma atuação a par- 
tir de estudos sobre os griots africanos e os jograis medievais europeus. Dissertação de mestrado apresentada ao Programa de Pós-graduação em Artes, Área de Concentração Artes Cênicas da UNESP. São Paulo: 2011.

SEMOG, Éle. Cultura, Identidade e Consciência. In: Rio Zumbi 2007 em REVISTA. Publicação do Governo do Estado do Rio de Janeiro, 2007.

SILVA, Saloma Salomão Jovino da. Capulanas Cia de Arte Negra: sob o signo da reinvenção. In: SILVA, Saloma Salomão Jovino da \& Capulanas (org.). \{EM\}GOMA: dos pés à cabeça, os quintais que sou. São Paulo: Capulanas, 2011.

\section{Fontes audiovisuais}

Keita L'heritage du griot. Direção de Dani Kouyaté, França/Burkina Faso: AFIX Productions, 1995.

Sotigui Kouyaté - Um Griot no Brasil. Roteiro e direção de Alexandre Handfest. São Paulo: SESC TV, 2007.

\section{Fontes orais}

BAMBA, Mahomed. Minicurso proferido durante o II Colóquio Internacional de Culturas Africanas - "Griots", Natal, RN, 2011.

BAMBA, François Moise. Entrevista realizada em Bobo-diulasso, Burkina Faso, África, 2015.

KOUYATÉ, Hassane. Por que contar histórias? O que contar? Como contar? - BOCA DO CÉU, 2012, 13, 14, 15 de setembro de 2012.

KOUYATÉ, Toumani. DJÉLIYA - a arte prática da transmissão na tradição oral mandingue. PAÇO DO BAOBÁ, 2013, 19 e 20 de outubro 2013.

KOUYATÉ, Toumani. Conto, instrumento de educação, de formação e de transmissão Tema: o conto - o contador de história - a escolha de seus contos - o repertório - os instrumentos do narrador - PAÇO DO BAOBÁ, 2014, de 20 a 24 de janeiro. 
RIBEIRO, Kelly Cristina (Keu Apoema). Depoimentos provenientes da artística em Burkina Faso e Mali no período de 19 dez. 011 a 19 fev. 2012, financiada pela Secretaria de Cultura do Estado da Bahia. Salvador, 2012.

Recebido em: 27/04/2015

Aprovado em: 02/07/2015 